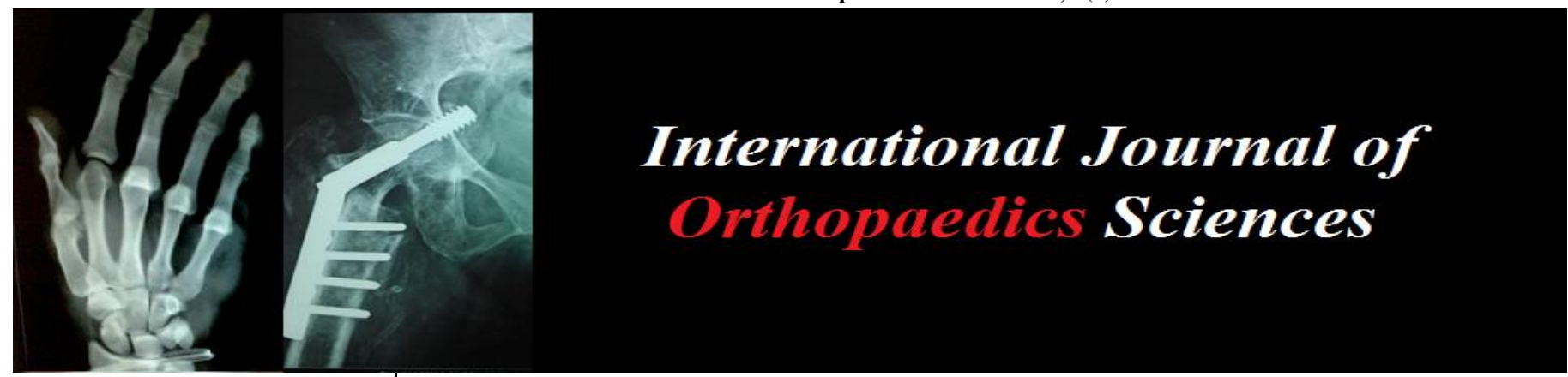

ISSN: $2395-1958$

IJOS 2018; 4(3): 598-600

(C) 2018 IJOS

www.orthopaper.com

Received: 14-05-2018

Accepted: 15-06-2018

Yash B Rabari

Senior Resident, Department of Orthopaedic, Rural Medical

Collage, Loni Bk, Maharashtra, India

\section{Amol Sanap}

Assistant Professor, Department of Orthopaedic, Rural Medical Collage, Loni Bk, Maharashtra, India

\section{Mayur Joshi}

Post Graduate Department of Orthopaedic, Rural Medical Collage, LoniBk, Maharashtra, India

\section{Parmindar Singh}

Post Graduate Department of Orthopaedic, Rural Medical Collage, Loni Bk, Maharashtra, India

\section{Mini open versus arthroscopic repair of rotator cuff tear: A prospective and retrospective study in rural area}

\author{
Yash B Rabari, Amol Sanap, Mayur Joshi and Parmindar Singh
}

DOI: https://doi.org/10.22271/ortho.2018.v4.i3k.104

\section{Abstract}

Background: Rotator cuff abnormalities (including degenerative tears and those due to injury) reportedly account for up to $70 \%$ of symptoms associated with the shoulder and have significant effects on quality of life and activities of daily living.

Material and Method: The objective of this study was to compare the use of resources, costs and healthrelated quality of life outcomes associated with arthroscopic and mini open surgical management of rotator cuff tears using follow-up of 2 years data from retrospectively and prospectively.

The study was conducted at Pravara Rural Hospital, an associate hospital of Rural Medical Collage Loni during the period of 2016 to 2018 .

Results: There are total 125 patient's data collected by retrospectively and prospectively. Among them 60 patient underwent mini open repair and 65 patient underwent arthroscopic repair of rotator cuff tear. There were, $41 \%$ female patient and $59 \%$ male patient in mini open repair, $53 \%$ female and $57 \%$ male patients in arthroscopic repair.

Conclusion: There is no significant difference in the functional outcome in the patient operated with mini open repair and arthroscopic repair.

There is a significant difference in patient's preference for surgery according to cost effectiveness as study conducted in rural area, so cost effectiveness is really matters for the patients coming from a poor background in rural area.

Keywords: Rotator cuff, arthroscopic, mini open

\section{Introduction}

Rotator cuff abnormalities (including degenerative tears and those due to injury) reportedly account for up to $70 \%$ of symptoms associated with the shoulder and have significant effects on quality of life and activities of daily living ${ }^{[1,2]}$.

Various forms of treatment are available for the symptomatic rotator cuff tear. Conservative management includes combinations of rest, exercise, physiotherapy, and pain relief. Surgery may also be undertaken to repair the tear using either an arthroscopic or open (including "mini-open") technique. Recent studies have shown that the number of rotator cuff procedures is increasing, in part due to a preference for minimally invasive techniques ${ }^{[3,4]}$.

However, there are not enough research about the relative costs and health-related quality of life outcomes of arthroscopic and open procedures to help justify the choice of surgery.

Our study was carried out to investigate the clinical and cost outcomes of arthroscopic and open procedures in patients with degenerative full-thickness rotator cuff tears retrospectively and prospectively.

\section{Material and Method}

The objective of this study was to compare the use of resources, costs and health-related quality of life outcomes associated with arthroscopic and mini open surgical management of rotator cuff tears using follow-up of 2 years data from retrospectively and prospectively.

\section{Inclusion criteria}

The patient must satisfy all the following criteria to be eligible for the study: of Orthopaedic, Rural Medical Collage, Loni Bk, Maharashtra, India 
- Aged over 50 years

- Suffer from a rotator cuff tear

- Have a full thickness rotator cuff tear

- Rotator cuff tear diagnosed using MRI or ultrasound scan

- Patient able to consent

\section{Exclusion criteria}

The patient may not enter the study if ANY of the following apply:

- Previous surgery on the affected shoulder

- Dual shoulder pathology

- Significant problems in the other shoulder

- Rheumatoid arthritis/systemic disease

- Significant osteoarthritis problems

- Significant neck problems

- Cognitive impairment or language issues

- Unable to undergo an MRI scan for any reason

The study is conducted at Pravara Rural Hospital, an associate hospital of Rural Medical Collage Loni during the period of 2016 to 2018.

The data, of operated patient of rotator cuff tear at pravara rural hospital 2 years back retrospectively and operated in may 2015 prospectively, collected with two year of follow up period.

The outcome of quality of life is measured through The American Shoulder and Elbow Surgeons Shoulder Score (ASES) after 2 years of follow-up by questionnaires.

The cost of surgery is measured by the material used for surgery (Implant, Suture Material) as ours is a charitable trust hospital so there are no operative charges, medicine charges and hospital stay charges. So comparison of cost effectiveness is done by material used for repair of rotator cuff as it is the only chargeable.

The final preference of surgery by cost effectiveness and quality of life of the patient after surgery is measured by questionnaires.

\section{Result}

There are total 125 patient's data collected by retrospectively and prospectively. Among them 60 patient underwent mini open repair and 65 patient underwent arthroscopic repair of rotator cuff tear. There were, $41 \%$ female patient and $59 \%$ male patient in mini open repair, 53\% female and $57 \%$ male patients in arthroscopic repair. (Table. 1)

Table 1: Gender Wise Distribution

\begin{tabular}{|c|c|c|}
\hline & Mini Open Group & Arthroscopic Group \\
\hline Male & 35 & 33 \\
\hline Female & 25 & 32 \\
\hline Total & 60 & 65 \\
\hline
\end{tabular}

The average age of the patient for rotator cuff tear is 58 year. (Table.2)

Table 2: Mean Age of the Patient in Year

\begin{tabular}{|c|c|c|}
\hline & Mini Open Group & Arthroscopic Group \\
\hline Male & 58 & 57 \\
\hline Female & 57 & 58 \\
\hline
\end{tabular}

All patients showed improvement in their modified ASES scores with surgery.

The initial modified ASES score for patients in the arthroscopic group averaged 50, and this improved to an average final score of $89\left(\mathrm{P}_{-} .05\right)$.

For patients in the mini-open group, the initial score averaged 43 , improving to an average final score of $88\left(\mathrm{P}_{-} .05\right)$.

The preoperative and postoperative modified ASES scores were not significantly different between groups $\left(\mathrm{P}_{-} .252\right.$ and $\mathrm{P}_{\text {_.333, respectively). }}$

In addition, the individual scores for pain, satisfaction, and function showed significant improvement for both groups. (Table. 3)

Table 3: Preoperative and Postoperative Modified ASES Scores (range) for Each Group

\begin{tabular}{|c|c|c|c|c|}
\hline & \multicolumn{2}{|c|}{ Mini Open Group } & \multicolumn{2}{c|}{ Arthroscopic group } \\
\hline & Pre Operative & Post Operative & Pre Operative & Post operative \\
\hline Pain (30 Points) & $13(1-22)$ & $27(19-30)$ & $15(5-25)$ & $26(18-30)$ \\
\hline Satisfaction (10 Points) & $3(0-10)$ & $9(5-10)$ & $2(0-10)$ & $9(5-10)$ \\
\hline Function (60 points) & $27(10-44)$ & $52(25-60)$ & $33(14-44)$ & $54(25-60)$ \\
\hline Total (100 points) & $43(9-48)$ & $88(50-100)$ & $50(10-52)$ & $89(50-100)$ \\
\hline
\end{tabular}

There are $70 \%$ in patients in the study who prefers mini open repair by the cost effectiveness as majority of the patients are from poor background.

\section{Discussion}

Although arthroscopic rotator cuff repair is a relatively new technique, several investigators have published reports of their short-term results for arthroscopic repair of fullthickness rotator cuff tears ${ }^{[5-15]}$.

Mini-open repair represented an attempt to combine the best features of arthroscopic and open repair. The ability to address intra-articular pathology and still repair the tendon with bone tunnels without taking down the deltoid origin has made mini open repair a popular technique. Short-term results of mini-open repair have been encouraging ${ }^{[16-18]}$.

Gartsman et al. reported on a series of 73 patients who had undergone arthroscopic rotator cuff repair and were followedup for a minimum of 2 years. Patients improved their ASES scores from an average of 30.7 to 87.6. Based on Constant and Murley scores, $84 \%$ of patients had either a good or excellent result ${ }^{[6]}$.

These results were similar to the results obtained with either open or mini-open repair and have provided a basis for the continued use of this technique ${ }^{[17,19-23]}$.

Servud and his colleagues compared 35 patients who had undergone mini-open repair with 29 patients with arthroscopic repair. At final follow-up, which averaged 44.6 months, there was no significant difference in function or range of motion. However, they reported that 4 of the 29 patients developed stiffness. Final outcome as measured by the ASES, UCLA, and SST scores were similar ${ }^{[10]}$.

\section{Conclusion}

There is no significant difference in the functional outcome in the patient operated with mini open repair and arthroscopic repair. 
There is a significant difference in patient's preference for surgery according to cost effectiveness as study conducted in rural area, so cost effectiveness is really matters for the patients coming from a poor background in rural area.

\section{References}

1. Teunis T, Lubberts B, Reilly BT, Ring D. A systematic review and pooled analysis of the prevalence of rotator cuff disease with increasing age. J Shoulder Elbow Surg 2014; 23:1913-1921.

2. Osborne JD, Gowda AL, Wiater B, Wiater JM. Rotator cuff rehabilitation: current theories and practice. Phys Sportsmed. 2016; 44:85-92.

3. Judge A, Murphy RJ, Maxwell R, Arden NK, Carr AJ. Temporal trends and geographical variation in the use of subacromial decompression and rotator cuff repair of the shoulder in England. Bone Joint J. 2014; 96-B:70-74.

4. Colvin AC, Egorova N, Harrison AK, Moskowitz A, Flatow EL. National trends in rotator cuff repair. J Bone Joint Surg [Am]. 2012; 94-A:227-233.

5. Gartsman GM, Khan M, Hammerman SM. Arthroscopic repair of full-thickness tears of the rotator cuff. J Bone Joint Surg Am. 1998; 80:832-840.

6. Gartsman GM, Brinker MR, Khan M. Early effectiveness of arthroscopic repair for full-thickness tears of the rotator cuff: An outcome analysis. J Bone Joint Surg Am 1998; 80:33-40.

7. Tauro JC. Arthroscopic rotator cuff repair: Analysis of technique and results at 2- and 3-year follow-up. Arthroscopy. 1998; 14:45-51.

8. Hata Y, Saito S, Murakami N, Seki H, Nakatsuchi Y, Takaoka K. A less invasive surgery for rotator cuff tear: Mini-open repair. J Shoulder Elbow Surg. 2001; 10:11-16.

9. Gleyze P, Thomazeau H, Flurin PH, Lafosse L, Gazielly DF, Allard M. [Arthroscopic rotator cuff repair: a multicentric retrospective study of 87 cases with anatomical assessment]. Rev Chir Orthop Reparatrice Appar Mot. 2000; 86:566-574.

10. Severud EL, Ruotolo C, Abbott DD, Nottage WM. Allarthroscopic versus mini-open rotator cuff repair: A longterm retrospective outcome comparison. Arthroscopy. 2003; 19:234-238.

11. Burkhart SS, Danaceau SM, Pearce CE Jr. Arthroscopic rotator cuff repair: Analysis of results by tear size and by repair technique-Margin convergence versus direct tendon-to-bone repair. Arthroscopy. 2001; 17:905-912.

12. Bennett WF. Arthroscopic repair of massive rotator cuff tears: A prospective cohort with 2- to 4-year follow-up. Arthroscopy. 2003; 19:380-390.

13. Ellman H, Kay SP, Wirth M. Arthroscopic treatment of fullthickness rotator cuff tears: 2- to 7-year follow-up study. Arthroscopy. 1993; 9:195-200.

14. Bennett WF. Arthroscopic repair of full-thickness supraspinatus tears (small-to-medium): A prospective study with 2- to 4-year follow-up. Arthroscopy. 2003; 19:249-256.

15. Jones CK, Savoie FH III. Arthroscopic repair of large and massive rotator cuff tears. Arthroscopy. 2003; 19:564571.

16. Hata Y, Saito S, Murakami N, Seki H, Nakatsuchi Y, Takaoka K. A less invasive surgery for rotator cuff tear: Mini-open repair. J Shoulder Elbow Surg. 2001; 10:1116.

17. Hersch JC, Sgaglione NA. Arthroscopically assisted miniopen rotator cuff repairs. Functional outcome at 2- to 7-year follow-up. Am J Sports Med. 2000; 28:301-311.

18. Blevins FT, Warren RF, Cavo C et al. Arthroscopic assisted rotator cuff repair: Results using a mini-open deltoid splitting approach. Arthroscopy. 1996; 12:50-59.

19. Bigliani LU, Cordasco FA, McIlveen SJ, Musso ES. Operative repairs of massive rotator cuff tears: Long-term results. J Shoulder Elbow Surg. 1992; 1:120-130.

20. Paulos LE, Kody MH. Arthroscopically enhanced miniapproach to rotator cuff repair. Am J Sports Med. 1994; 22:19-25.

21. Hawkins RJ, Misamore GW, Hobeika PE. Surgery for fullthickness rotator-cuff tears. J Bone Joint Surg Am. 1985; 67:1349-1355.

22. Ellman H, Hanker G, Bayer M. Repair of the rotator cuff. End-result study of factors influencing reconstruction. J Bone Joint Surg Am. 1986; 68:1136-1144.

23. Shinners TJ, Noordsij PG, Orwin JF. Arthroscopically assisted mini-open rotator cuff repair. Arthroscopy. 2002; $18: 21-26$. 